\title{
ЛЕКСИКО-СЕМАНТИЧЕСКИЕ ОСОБЕННОСТИ КОНЦЕПТА «СЕМЕЙНЫЙ УКЛАД» В АНГЛИЙСКОМ ЯЗЫКЕ
}

\section{LEXICAL AND SEMANTIC FEATURES OF THE CONCEPT OF [WAY OF FAMILY LIFE $\square$ IN ENGLISH LANGUAGE}

Iu. Ryndina

Summary: The concept «way of family life» is one of the unique concepts in the English language picture of the world since it reflects the mental, cultural and behavioral characteristics of the English. This article is devoted to the description of the concept «way of family life» based on the material of English dictionaries. The main areas of research were: analytical (analysis of theoretical literature and factual material on the research topic), continuous sampling method, lexical and semantic analysis. The scientific novelty of the study is to supplement and deepen the existing ideas about the concept «way of family life» in the English language picture of the world on the material of explanatory dictionaries of the English language. The results of the study can be used in the practice of teaching lexicology and stylistics of the English language.

Keywords: concept, way of family life, representation of the concept, the lexico-semantic analysis, the language picture of the world.

\author{
Рындина Юлия Валерьевна \\ К.п.н., доцент, Ииимский педагогический институт \\ им. П.П. Ершова (филиал) ВГАОУВО \\ «Тюменский государственный университет») \\ y.v.ryndina@utmn.ru
}

Аннотация: Концепт «семейный уклад» мы относим к уникальным концептам английской языковой картины мира, поскольку в нем отражаются ментальные, культурные и поведенческие особенности англичан. Данная статья посвящена описанию концепта «семейный уклад» на материале словарей английского языка. Основными направлениями исследования послужили: аналитический (анализ теоретической литературы и фактического материала по теме исследования), метод сплошной выборки, лексико-семантический анализ. Научная новизна исследования заключается в дополнении и углублении существующих представлений о понятии «семейный уклад» В английской языковой картине мира на материале толковых словарей английского языка. Результаты проведенного исследования могут быть использованы в практике преподавания лексикологии и стилистики английского языка.

Ключевые слова: концепт, семейный уклад, репрезентация концепта, лексико-семантический анализ, языковая картина мира.

\section{Актуальность проведенного исследования}

K онцептосфера представляет собой одну из наиболее значимых сфер в системе знаний человека о языковой картине мира любого народа. Изучение различных концептов, связанных с укладом семьи, вносит существенный вклад в развитие таких отраслей научного знания как когнитивная лингвистика, лингвострановедение, лингвокультурология, межкультурная коммуникация.

Несмотря на то, что в теории и практике лингвистического образования накоплен определённый опыт концептологических исследований, концепт «семейный уклад» не подвергался ранее самостоятельному изучению. Мы считаем данный концепт ключевым элементом в понятийном аппарате человеческого сознания. Поэтому его изучение представляет для нас особый интерес, так как оно открывает широкие перспективы для раскрытия глубинной универсальности понятийного аппарата лингвистики.

\section{Результаты проведенного исследования}

Для более полного описания концепта «семейный уклад» мы посчитали важным выполнить теоретический анализ данного понятия на основе педагогической, психологической, философской, экономической и лингвистической литературы.

Так, в современном толковом словаре русского языка мы находим следующие значения данной дефиниции: «установленный или установившийся порядок, сложившийся образ жизни кого-либо или чего-либо (человека, семьи, социальной группы и т.п.); экономическая форма, тип ведения хозяйства в рамках какой-либо общественно-экономической формации» [17, с. 864].

В философской литературе понятие «уклад» рассматривается с общественно-экономической точки зрения. Так, по мнению Ю.И Семенова, уклад - это «более или менее сформированная совокупность производственных отношений, образующая самостоятельную, отличную от остальных систему общественного хозяйства» [16, с. 26].

Анализ этих определений показывает, что понятие «уклад» употребляется по отношению к человеку, группам людей и обществу в целом, предполагает совокупность общественных отношений, некое постоянство и порядок в функционировании общества и каждого человека в отдельности. В психолого-педагогических и лингвистических словарях этот термин нам не встретился. 
Интересными в свете нашего исследования является труд Т.А. Берсеневой, в котором она рассматривает понятие «уклад жизни». По мнению ученого, это «установившийся порядок отношений, отраженный в образе жизни и включающий в себя сложившуюся систему духовнонравственных ценностей, усвоенную предшествующими поколениями и направленную на закрепление в следующих поколениях идеалов, смыслов, норм и распорядка жизни» [4, с. 20]. Учёный подчеркивает важность изучения понятия «уклад жизни» как «гарантии сохранения этнического многообразия, социальной устойчивости и эффективной экономической политики государства» [4, с. 27].

В психологической литературе понятие «семейный уклад» рассматривалось в работах Т.В. Андреевой [1], В.М. Бехтерева [5], О.А. Карабановой [10] и др. Так, B.М. Бехтерев предложил концепцию возникновения семьи, согласно которой «ключевая причина формирования семей связана с наличием инстинкта размножения, стремлением человека выжить» [5, с. 60]. Само понятие автор рассматривал как «...совокупность условий совместной жизни...» [5, с. 60]. Т.В. Андреева под семейным укладом понимает «структуру власти в семье» [1, с. 68]. О.А. Карабанова трактует уклад семьи через «систему ценностей, семейное самосознание и распределение ролей в семье» [10, с. 34].

Ф.И. Кевля, А.А. Огаркова и Е.Н. Рыднина рассматривают понятие «семейный уклад» с концепции системного подхода. По мнению ученых, семейный уклад конкретной семьи проявляется «в установившемся порядке её жизни и стиле отношений друг с другом; в её установках, потребностях, интересах, традициях, ценностных ориентациях; в уровне психолого-педагогической культуры родителей; в здоровье всех членов семьи» [11, с. 40].

Итак, анализ психолого-педагогической литературы по проблеме исследования позволил сделать вывод об отсутствии единого подхода к категориальному статусу дефиниции «семейный уклад».

О.М. Потаповская выделяет следующие пять составляющих семейного уклада: обычаи; традиции; отношения; правила и привычки; распорядок дня, недели, года» $[14$, c. 20].

Р. Бернс в содержание понятия «семейный уклад» включает также «воспитательный стиль родителей, размеры семьи и старшинство среди детей» [3, с. 135].

По мнению В.Н. Куницыной и Е.А. Юмкиной, «для понимания особенностей семейного уклада необходимо рассмотреть и среду, в которой эти отношения развертываются» [13]. В смысловое содержание семейного уклада авторы включают «состав семьи, включая прародителей; иерархию внутри семьи; межличностные отно- шения; ведение хозяйства, обустройство дома; контакты с ближайшим и дальним окружением; порядки внутри семьи, наличие семейного сценария» [13].

Проанализировав понятие «семейный уклад» с позиций различных наук мы пришли к выводу, что в смысловом содержании семейный уклад является интегральным понятием, включает в себя материальную, эмоциональную, интеллектуальную и нравственную составляющие жизни семьи. Он проявляется в составе семьи, системе взаимоотношений членов семьи друг с другом, быте, семейных традициях и порядках, а также в контактах семьи с близким и дальним окружением. Следует отметить, что все составляющие семейного уклада взаимосвязаны и взаимообусловлены.

Концепт «семейный уклад» не был ранее предметом лингвистических исследований. Однако в языковедении имеется ряд работ, посвященных исследованию концептов, близких или пересекающихся по своему содержанию с концептом «семейный уклад». Такими концептами являются концепты «семья», «брак», «родственные отношения», «быт», «дом».

Так, Ю.В. Каменская рассматривает концепт «семья» с помощью фреймовой модели. Учёный выделяет в ней следующие терминалы: «нуклеарная семья (семья, состоящая из мужа, жены и детей, живущих под одной крышей), патриархальная семья (совместное проживание нескольких поколений родственников), жизнь семьи (знакомство будущих супругов, создание семьи, рождение и воспитание детей, жизнь супругов после того, как выросли дети)» $[9$, с. 80].

М.А. Терпак проанализировала концепт «родственные отношения» с помощью когнитивного анализа. По мнению исследователя, данный концепт отражает «представления народа о доме, семье, кровнородственных отношениях и родстве по супружеству» [18, с. 3]. В своем исследовании М.А. Терпак приходит к выводу о «значительном консерватизме и традиционализме семейного уклада в английской лингвокультуре» [18, с. 17].

По мнению Е.В. Добровольской, концепт «семья/ family» можно трактовать как «совокупность живущих вместе родственников (семья - дом) или совокупность кровных родственников (семья - родные), связанных различными межличностными отношениями» $[7$, с. 6].

А. Биктагирова сопоставляет различные культурные коды концепта «семья» в английском, турецком и татарском языках. Ученый приходит к выводу о признании в данных лингвокультурах «мужской власти и женской зависимости в браке, святости только первого брака, положительном отношении к поздним бракам (английская лингвокультура)» [6, с. 110]. 
H.Н. Занегина, рассматривая концепт «семья/family» как гиперконцепт, выделяет в нем такие компоненты как «семейство», «гнездо», «фамилия», «дом», «двор», «домочадцы», «династия», а также «формально чужих людей, если они воспринимают друг друга как родственников, и домашних животных» [8, с. 4].

Анализ толковых словарей английского языка позволил выделить следующие значения существительного «family»: «the unit consisting of parents and their children; nuclear family (Twenty families live on our street.); a group of people connected by blood or marriage; relatives (My family is very large.); children (Have you any family?); a group of individuals living under one roof and usually under one head; a group of people descended from a common progenitor; house, line, or clan (Her mother's family had lived there for generations.); biol. A group of related animals or plants, ranking below an order and above a genus (Zebras, asses, and horses belong to the horse family.); people you love and love you back, not necessarily blood or biological, but you trust them and they trust you, and they take care of you and you take care of them; a group of people or things with a common or related characteristic, function or origin; a class of languages sharing certain characteristics and seeming to have had a common origin (The English language belongs to the Indo-European family.); things that belong to a particular family (Ben worked in the family business.); things that are designed to be used or enjoyed by both parents and children (a family car, family entertainment)» $[20,23,24,25,26]$.

Итак, под понятием «family» следует понимать группу лиц, связанных узами родства или брака и живущих вместе.

Понятие «уклад» относится к пласту безэквивалентной лексики, однако в английском языке его значение можно передать с помощью лексем lifestyle, way of life, behavior, conduct, habits, style of living, way of acting. Ha наш взгляд, более близкими по значению к понятию «уклад» являются лексемы lifestyle и way of life. Paсcмотрим их подробно.

В словаре Merriam-Webster мы находим следующее толкование понятия «way of life»: «the habits, customs, and beliefs of a particular person or group of people; an important activity that affects all parts of someone's life» [21].

В словаре Dictionary.com мы находим следующее определение понятию «lifestyle»: «the habits, attitudes, tastes, moral standards, economic level that together constitute the mode of living of an individual or group» [22].

Словарь Vocabulary.com описывает понятие «lifestyle» следующим образом: «Your lifestyle is how you live, and it reflects who you are. You might try to look cool by adopting a rock star lifestyle of partying every night and sleeping all day, but you'd probably get pretty tired. A lifestyle can also reflect your attitude or your personal values. For example, you might have a very conservative lifestyle, which means you don't spend money on anything trivial or unnecessary, and you don't engage in silly activities. A glamorous lifestyle means you indulge in upscale, high-profile pursuits and live luxuriously. If you have got some bad habits, your doctor might encourage you to adopt a healthier lifestyle, and get more exercise and eat more carefully» [27].

Merriam-Webster дает следующее определение понятию «family life»: «the kind of life a person normally leads when one is married and has children» [21].

Близкими к рассматриваемому нами концепту являются также domestic life, family model, family patterns, household practices, описывающие структуру семьи, взаимоотношения между ее членами, семейный быт и традиции.

Мы полагаем, что понятие «семейный уклад» является концептуально синонимичным понятию «дом». Следует отметить также диссертационное исследование Е.С. Баландиной, в котором учёный доказывает, что слово «семья» в русской, английской и американской лингвокультурах стало символически заменяться словом «родительский дом» [21, с. 20]. В английском языке понятие «дом» представлено лексемами «house» и «home». Рассмотрим их подробно.

Основные значения понятия «house» в толковых словарях английского языка представлены следующим образом: «оne of the divisions of a school for sports competitions; a building made for people to live in, usually designed for one family; a building for a government assembly; a family or dynasty, the royal house of Tudors; a building or establishment for a special purpose (the opera house)» $[20,21,23,25,26,27]$.

По данным этих же словарей лексема «home» имеет следующие значения: «the place where you live; a place where those who need help are looked after; the place where you were born or where you feel you belong; the place where a child lived with his or her family; a house, apartment etc. considered as property which you can buy or sell; the country where you live, as opposed to foreign countries; the place where you feel comfortable, happy or confident, relaxed» $[20,21,23,25,26,27]$.

Анализ значений данных понятий позволил нам сделать вывод, что концепт «house» в английской языковой картине мире используется для обозначения строения. При этом часть концепта «hоте» характеризуется большей абстрактностью; оно служит для описания «особенной атмосферы внутри определенного дома, «своего» пространства, «средоточия семьи». 
Итак, в английской языковой картине мире понятие «дом» воспринимается главным образом как конкретный объект, собственная территория, способная выразить индивидуальность своего владельца и подтвердить его положение в обществе.

Близким к исследуемому нами концепту является концепт «брак», который рассматривается Е.А. Кудиновой в контексте его лексической репрезентации в русском и немецком языках с точки зрения этнолингвистики. Ученый отмечает «этимологическое несоответствие и нетождественность данного концепта в сравниваемых языках, что связано со специфической представленностью его в языковом сознании русских и немцев» [12, с. 98].

Концепт «быт» является одной из малоизученных областей в современной лингвистической науке. Так, А.В. Рудакова выделяет шесть когнитивных слоев данного концепта: «домашнее хозяйство, предметы домашнего обихода; типичная бытовая деятельность, сложившийся порядок жизни, повседневная жизнь человека; семья, семейная, домашняя жизнь и характер взаимоотношений между людьми; жизнь, существование человека [15, с. 4]. Исследований, посвященных изучению концепта «быт» на материале английского языка мы не нашли.

Для нашего исследования мы считаем важным рассмотреть лексемы «household» и «housekeeping», характеризующие быт англичан и распределение семейных обязанностей.

Словарь Cambridge dictionary дает следующее толкование понятия «household»: «a group of people, often a family, who live together» [19].

Синонимический ряд данного понятия представлен лексемами extended family, home, house, ménage, domestic, familial.

В онлайн-словаре Dictionary.com мы находим следующие дефиниции слова «housekeeping»: «the maintenance of a house or domestic establishment; the management of household affairs; the management, care, and servicing of property and equipment of an industrial or commercial building or organization; the ongoing routine, procedures, operations, and management of a commercial enterprise, government, organization, or the like» [22].

Синонимический ряд данного понятия представлен лексемами housework, housewifery, domestic science, home economy.

Сравнительный анализ понятий «household» и «housekeeping» позволил сделать вывод о существенном различии между данными лексемами. Понятие «household» - это совокупность всех людей, живущих в конкретном доме; семья, включая прислугу и т.д.; домашнее хозяйство или семейное учреждение, в то время как «housekeeping» - это работа по поддержанию дома как места жительства в чистоте (например, уборка). Как прилагательное «household» - это принадлежность к одному и тому же дому и семье.

Семейный уклад представлен также семейными порядками и правилами. В английском языке это слово «house rule», которое можно определить как «а rule or regulation that applies among a family members at home» [21].

Итак, анализ значений словарных дефиниций позволил дать авторское определение концепта «семейный уклад» на английском языке: way of family life is the established way of life of a particular family, which includes common rules of behavior, beliefs, interests, traditions, activities and relationships.

Мы полагаем, что основные рассуждения о способах языковой репрезентации рассматриваемого нами концепта могут быть сведены к трем основным логемам. Первая логема подразумевает семейные традиции и быт конкретной семьи, т.е. ее привычные формы поведения, переходящие из поколения в поколение. Вторая логема отражает взаимоотношения между членами семьи, структуру семьи, воспитательный стиль родителей. Третья логема отражает правила, нормы поведения, привычки (распорядок дня, недели, года). Предлагаемое нами описание структуры концепта «семейный уклад» не является окончательным исследованием, а представляет собой результаты начального этапа нашей исследовательской работы.

В заключение подчеркнем, что настоящее исследование не исчерпывает всего содержания рассматриваемой проблемы. Накопленный теоретический и фактический материал требует развития и уточнения. Тем не менее в нашей работе были освещены существенные аспекты исследования концепта «семейный уклад» на материале словарей английского языка. Перспективу дальнейшего изучения данной проблемы мы видим в описании структуры лексико-семантического поля концепта «семейный уклад» на материале художественных текстов.

\section{ЛИТЕРАТУРА}

1. Андреева Т.В. Семейная психология: учеб. пособие. СПб.: Речь, 2004. 224 с.

2. Баландина Е.С. Динамика образа семьи в языковом сознании носителей разных культур: автореферат дис. ... канд. фил. наук: 10.02.19 Екатеринбург, 2013. $22 \mathrm{c}$ 
3. Бернс Р. Развитие Я-концепции и воспитание: пер. с англ. М.: Прогресс, 1986. 421 с.

4. Берсенева Т.А. Духовно-нравственные основания традиционного уклада жизни как социально-педагогическая проблема: дис. ... д-ра пед. наук. Курск, 2008. 432 c.

5. Бехтерев В. М. Избранные работы по социальной психологии. М.: Наука, 1994. 400 с.

6. Биктагирова 3.А. Лингвокультурологические особенности паремий о семье (на материале английского, турецкого и татарского языков) // Вестник ЧГУ. 2006. №5. С. 107-112

7. Добровольская Е.В. Концептуализация семьи в русской языковой картине мира: автореферат дис. ... канд. филол. наук: 10.02.01 / Том. гос. ун-т. - Томск, 2005. $24 \mathrm{c}$.

8. Занегина Н.Н. Концепт «семья» в русском литературном языке и принципы его описания: автореферат дис. ... канд. филолог. наук: 10.02.01. Москва, 2011.25 c.

9. Каменская Ю.В. Фрейм «семья» в диалектной картине мира // Альманах современной науки и образования. Тамбов: Грамота, 2008. Ч. 2. №8 (15). С. 79-82.

10. Карабанова 0.А. Психология семейных отношений и основы семейного консультирования. М.: Гардарики, 2005.320 с.

11. Кевля Ф.И., Рыднина Е.Н., Черствая 0.Е. Семья и семейный уклад в России: монография. М.: «Русь», 2006. 137 с.

12. Кудинова Е.А. Лексическая репрезентация концепта «брак» в русском и немецком языках // Альманахсовременной науки и образования. Тамбов: Грамота, 2008. ч. 2. №8 (15). С. 97-98.

13. Куницына В.Н., Юмкина В.Н. Семейный уклад в социально-психологическом аспекте // Современные проблемы науки и 0бразования. - 2012. № 4. URL: http://science-education.ru/ru/article/view?id=6696

14. Потаповская 0.М. Педагогическое сопровождение семьи в вопросах духовно-нравственного воспитания детей. 2-е изд., перераб. и доп. М.: Планета $2003.64 \mathrm{C}$.

15. Рудакова А.В. Объективация концепта «быт» в лексико-фразеологической системе русского языка: автореферат дис. .... канд. филолог. наук : 10.02 .01 / Воронеж. гос. ун-т. Воронеж, 2003. 22 с.

(c) Рындина Юлия Валерьевна (y.v.ryndina@utmn.ru).

Журнал «Современная наука: актуальные проблемы теории и практики»

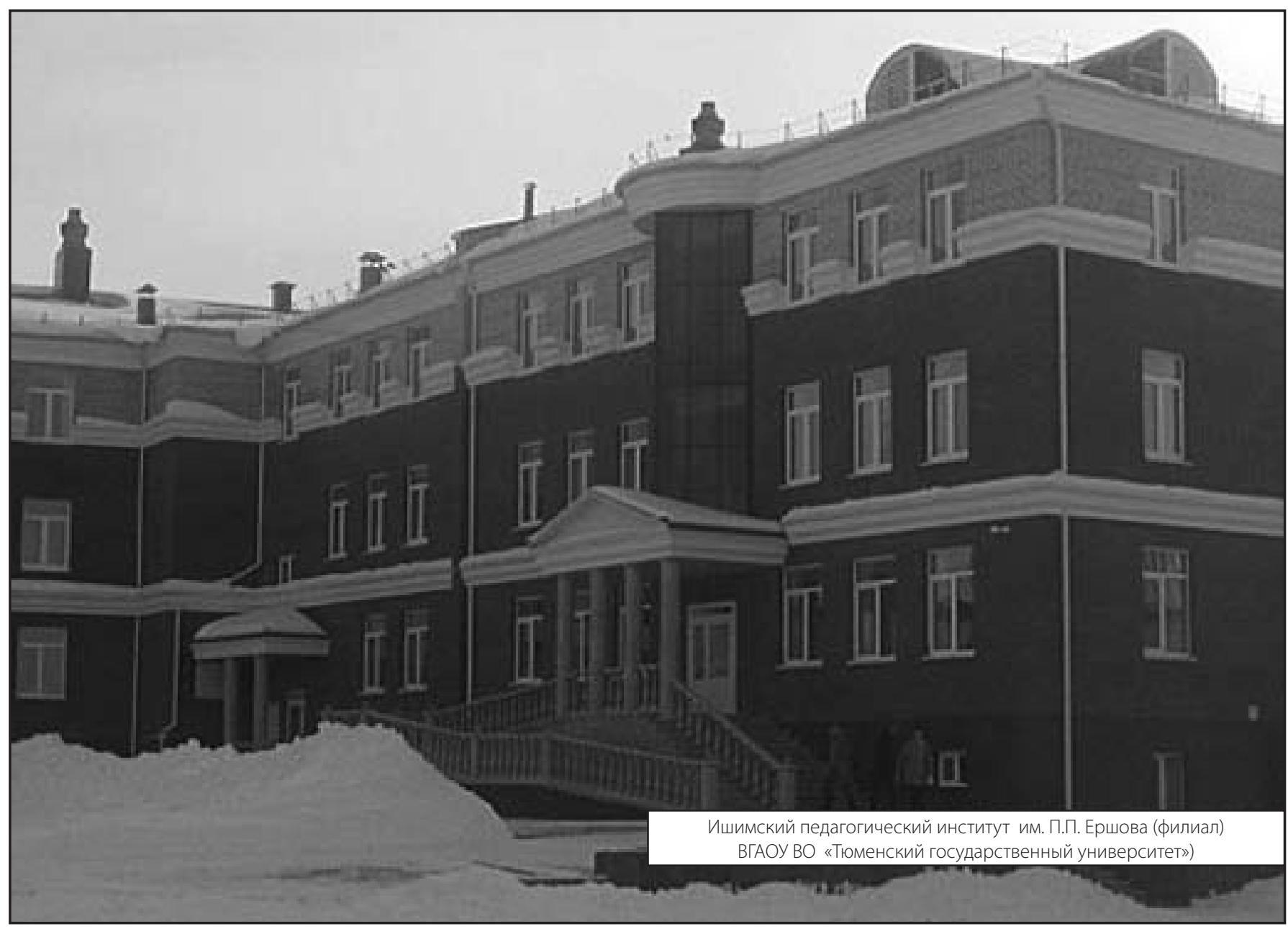

